\title{
New therapeutic options in the management of COPD - focus on roflumilast
}

\author{
Sabina Antonela Antoniu \\ University of Medicine and Pharmacy, \\ Pulmonary Disease Division, \\ Pulmonary Disease University \\ Hospital, lasi, Romania
}

This article was published in the following Dove Press journal: International Journal of COPD

I7 February 201 I

Number of times this article has been viewed

\begin{abstract}
In chronic obstructive pulmonary disease (COPD) the inflammation occurring in the airways and in other lung tissues is complex and is orchestrated by various mediators including the isoenzyme 4 of the phosphodiesterases family (PDE4), which contributes to bronchoconstriction and inflammation. Various PDE4 inhibitors have been evaluated as potential therapies in asthma or COPD but among these only roflumilast have been authorized in Europe to be used in patients with severe COPD as an add-on to the bronchodilator therapy. This review discusses the existing preclinical and clinical data supporting the use of roflumilast for this therapeutic indication and tackles some of the pending issues related to PDE4 in general and to roflumilast in particular.
\end{abstract}

Keywords: COPD, roflumilast, PDE4, efficacy, safety

\section{Introduction}

COPD is an inflammatory disease of the airways related mainly to smoking and characterized by airflow limitation, which manifests clinically with dsypnea, cough, and sputum production, symptoms that aggravate disease severity and disease exacerbation.

Chronic airways inflammation leads to their progressive obstruction, lung parenchyma damage, and mucus hypersecretion. Subsequently these result in abnormalities in gas exchange at the pulmonary level and respiratory failure.

Currently COPD is classified in 4 stages of severity depending on the degree of airways obstruction measured by $\mathrm{FEV}_{1}$ and with $\mathrm{FEV}_{1} / \mathrm{FVC} \%$ ratio (Table 1).

In COPD the therapeutic approach is aimed at treating disease exacerbation when this occurs and at slowing disease progression in the stable state. In the latter, smoking cessation is the main therapeutic intervention able to slow significantly disease progression in smoking-related COPD. Apart from smoking cessation, other therapeutic approaches such as bronchodilator and anti-inflammatory therapies are applied differently according to the disease severity in order to reduce airway obstruction, the underlying inflammation, the progression of respiratory symptoms, and the risk of exacerbations (Table 1$){ }^{1}$

Several classes of bronchodilators are used in the treatment of stable COPD such as inhaled $\beta 2$ agonists (short- and long-acting), inhaled anticholinergics (short- or long-acting), and methylxantines. These therapies were found to improve lung function especially on a short-term basis and were also reported to significantly ameliorate health-related quality of life, by reducing dyspnea levels and increasing exercise capacity. ${ }^{1}$
Correspondence: Sabina Antonela Antoniu "Gr. T. Popa" University of Medicine and Pharmacy, Pulmonary Disease Division, Pulmonary Disease University Hospital, 30 Dr I Cihac Str, 700 I I5, lasi, Romania Tel +40 232239408 ext II I Email sabina.antonela.antoniu@pneum. umfiasi.ro 
Table I Stable COPD classification and current pharmacologic therapies according to the disease severity'

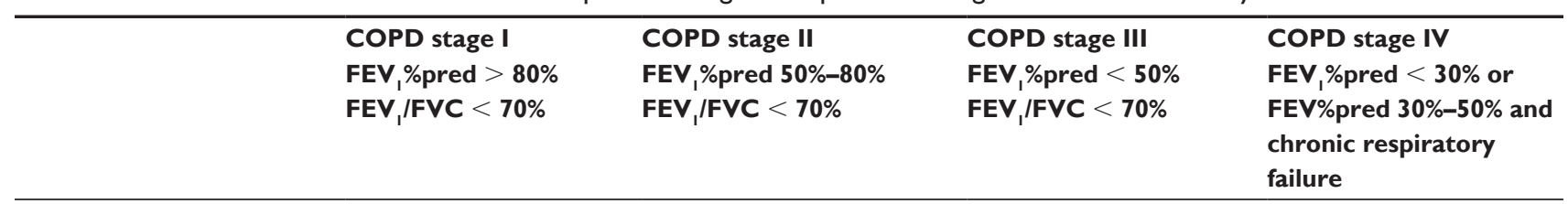

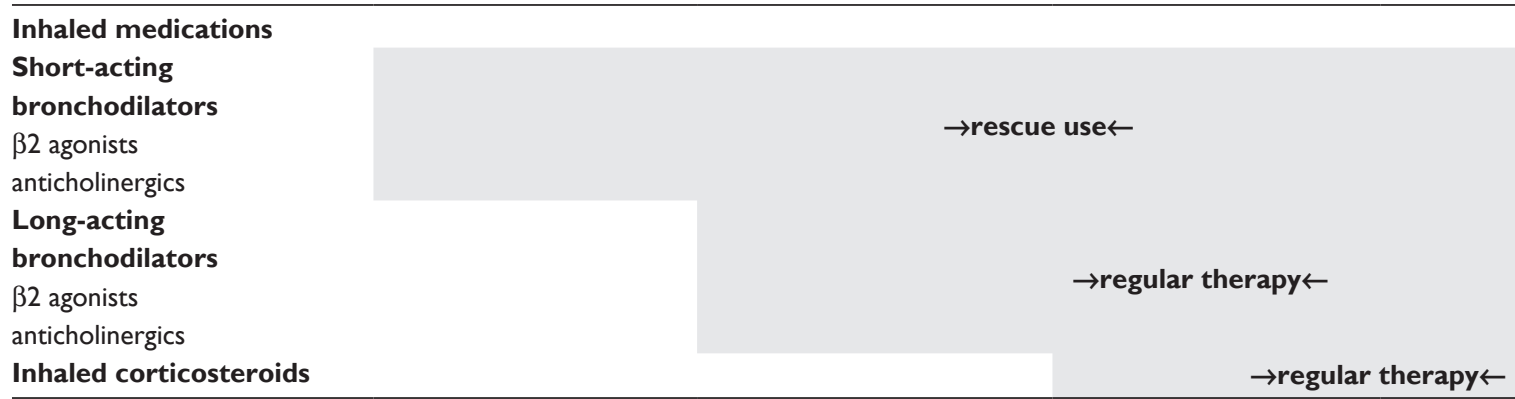

Inhaled corticosteroids $\quad \rightarrow$ regular therapy $\leftarrow$

Notes: www.goldcopd.com The GOLD Workshop Report (Updated 2008): Global strategy for the diagnosis, management and prevention of chronic obstructive pulmonary disease.

Inhaled corticosteroids still represent the main antiinflammatory treatment in COPD despite more modest clinical efficacy than in asthma, due to a less "corticosteroid-sensitive" pattern of inflammation. Again unlike asthma, in COPD this type of medication is given only in more advanced stages (III and IV), usually combined with long-acting $\beta 2$ agonists in order to reduce the number of exacerbations. ${ }^{1-3}$

\section{COPD pathogenesis}

The main inflammatory cells involved in COPD pathogenesis are CD8+ (cytotoxic) T-lymphocytes, macrophages, and neutrophils which interact to develop and maintain a chronic inflammation in the airways and other lung tissues. ${ }^{1,4}$

CD8+ (cytotoxic) T-lymphocytes have been found in high numbers in biopsies of smoking-induced COPD patients, and it is thought that they interact with activated CD4+ T-lymphocytes in order to produce various proinflammatory mediators such as interleukin (IL)-2, interferon- $\gamma$ (IFN- $\gamma$ ), tumor necrosis factor- $\alpha$ (TNF- $\alpha)$, perforines, or granzymes which are directly involved in alveolar tissue destruction. ${ }^{4-6}$ Macrophages were also detected in the airways of patients with COPD and they play an potentiating role for the underlying neutrophilic inflammation, especially by producing mediators such as TNF- $\alpha$ or leukotriene B4. ${ }^{1,4,7}$

In COPD neutrophils are responsible mainly for synthesis and release of proteinases and reactive oxygen species, which destroy normal lung tissue and stimulate mucus hypersecretion. ${ }^{8}$

\section{Targeting PDE4 pathway in COPD}

Phosphodiesterases (PDEs) are cAMP-, or cGMP-specific enzymes which have a ubiquitous distribution in the human organism. To date 11 isoenzyme groups with various isoforms have been identified. ${ }^{9}$ Of particular interest for this review is the PDE4 isoenzyme, which hydrolyzes cAMP and is expressed in lung structural cells such as smooth muscle cells, airway epithelium, and inflammatory cells such as neutrophils, lymphocytes, or macrophages. ${ }^{10}$

PDE4 has emerged over the past 2 decades as a promising therapeutic target in airway inflammatory diseases such as asthma or COPD. The initial focus was on asthma based on the assumption that PDE4 inhibition would result in bronchodilation and reduction of underlying eosinophilic inflammation. However, subsequent results of preclinical testing showing potent anti-inflammatory effects on patterns of inflammation rather similar to those of COPD, as well as a modest bronchodilatory effect, that drew attention to PDE4 inhibition for COPD.

Several PDE4 inhibitors were developed, including initially rolipram, cilomilast, and roflumilast. Among these, roflumilast was the first to be developed and approved for market (in Europe) as a COPD therapy.

\section{Nonspecific inhibition of PDE4 in COPD: the role of methylxantines}

Methylxantines, although no longer commonly used due to their limited efficacy, are rather known for their bronchodilator activities. However they also have been demonstrated to exert a range of anti-inflammatory activities on various inflammatory pathways such as arachidonic acid metabolites, TNF- $\alpha$, nuclear factor- $\kappa \mathrm{B}$, phosphoinositide 3-kinase, or PDEs. ${ }^{11,12}$

Theophylline is a methylxanthine most known and used in COPD treatment as a second-line bronchodilator, although 
its efficacy is counterbalanced by its narrow therapeutic range of plasma concentrations $(10-20 \mathrm{mg} / \mathrm{L})$, poor tolerability and safety profile. ${ }^{13}$ The bronchodilator activity of theophylline is believed to be due to its nonselective inhibition of PDEs in airway smooth muscle cells. ${ }^{12,14,15}$

In COPD patients short-term treatment with high doses of theophylline given alone or as an add-on therapy to other bronchodilators and corticosteroids improved lung function and respiratory symptoms such as dyspnea. ${ }^{16,17}$

In terms of anti-inflammatory activities, theophylline given to COPD patients dosed to achieve plasma levels lower than or within the range 9 to $11 \mathrm{mg} / \mathrm{L}$ to produce bronchodilation, reduced neutrophil count, IL-8, myeloperoxidase, and neutrophil elastase levels in sputum. ${ }^{18-23}$

Theophylline was demonstrated to be a weak and nonselective inhibitor of several PDE isoforms in the airways, such as PDE3, -4, and -5, which was hypothesized to cause the bronchodilation. ${ }^{14}$ Its nonselectivity might also explain the occurrence of side effects such as nausea or headaches which are caused by PDE4 inhibition. ${ }^{24}$

\section{Selective PDE4 inhibition in preclinical studies in asthma and COPD: focus on roflumilast}

Roflumilast (3-cyclo-propylmethoxy-4-difluoromethoxy-N[3,5-di-chloropyrid-4-yl]-benza mide) was identified as a potent and selective PDE4 inhibitor and was demonstrated to increase the levels of intracellular cAMP to a lesser extent in the bronchial smooth muscle cells and to a greater extent in inflammatory cells such as neutrophils, monocytes, dendritic cells, or CD4+ T cells, and in the epithelial cells of the airways and pulmonary vessels: the most striking effects were reported in vitro with both roflumilast and its metabolite roflumilast $\mathrm{N}$-oxide on leukotriene $\mathrm{b} 4$, reactive oxygen species, TNF- $\alpha$, IFN- $\gamma$, or granzyme B. ${ }^{15,25,26}$

Some of the studies evaluated the effects of roflumilast in asthma animal models whereas most evaluated this PDE4 inhibitor in animal models of COPD.

Roflumilast was assessed in an ovalbumin (OVA)-sensitized and challenged Brown Norway rat model, and its antiinflammatory activities were compared with those of other PDE4 inhibitors, rolipram, piclamilast, and cilomilast. Animals received these treatments before OVA challenge and airway hyper-responsiveness (AHR), and brochoalveolar lavage (BAL), neutrophil counts and TNF- $\alpha$ levels were quantified after allergen challenge. Roflumilast was found to be the most potent inhibitor of AHR and of neutrophil influx in the lungs among the compounds tested, and also demonstrated the greatest suppressing effects on TNF- $\alpha$. However roflumilast had no effect on serotonin-induced bronchoconstriction, suggesting that this compound had anti-inflammatory rather than bronchodilating effects. ${ }^{27}$

cAMP has an inhibitory effect on cell proliferation and therefore it has been postulated that PDE4 inhibitors might exert an antiremodeling effect on the airways. ${ }^{10}$

In OVA-sensitized and challenged guinea pigs, roflumilast given again before OVA-challenge reduced AHR and the release of cysteinyl leukotrienes. ${ }^{28}$

The anti-inflammatory effects of roflumilast might also result in a reduction of airway remodeling, as demonstrated in a study performed in a mice asthma model with chronic allergen exposure in which roflumilast, given after the allergic inflammation developed, demonstrated antifibrotic effects comparable with those of dexamethasone. ${ }^{29}$ Roflumilast $\mathrm{N}$-oxide, the active metabolite of roflumilast, inhibited TNF- $\alpha$-induced ICAM- 1 and eotaxin release in human fetal lung fibroblast cell line bFGF, and TGF $\beta 1$ profibrotic activities. ${ }^{30}$

In an animal model of tobacco-induced COPD, roflumilast given after smoking-related lung inflammation had developed, reduced the recruitment of neutrophils from the lung microvasculature and the BAL protein content. ${ }^{31}$ When given in a rat model of exacerbated COPD, roflumilast reduced BAL neutrophil count and mucus hypersecretion. ${ }^{32}$ The anti-inflammatory effects of roflumilast in the initial experiments were found to be quite heterogeneous in terms of amplitude and the type of inflammatory cell targeted by this compound, probably a result of the limited exposure to tobacco smoke. ${ }^{33}$ A subsequent study demonstrated that the anti-inflammatory effects of roflumilast differed according to inflammation pattern: for example in a model of neutrophilic airway inflammation induced by "acute" smoking exposure, roflumilast given in 2 different dosages reduced the number of these cells, whereas in a chronic smoke exposure model the anti-inflammatory effects were reported only with the higher dose and consisted of a reduction in macrophage inflammation and the size of emphysema lesions, and in preservation of lung desmosine content, but had no effect on goblet cell metaplasia. ${ }^{34}$ Furthermore in a chronic exposure model a lower dose of roflumilast was effective against the recruitment of dendritic cells and T-lymphocytes, whereas the higher dose had a "universal" anti-inflammatory effect on all inflammatory cell types. ${ }^{35}$

In EGF-stimulated human airway epithelial cells (A549) line and in human isolated bronchial tissue, roflumilast reduced EGF-related increase in MUC5AC gene and 
protein expression, its inhibitory effect being more potent than that of other PDE4 inhibitors such as rolipram or cilomilast. ${ }^{36}$

\section{Roflumilast: clinical data in COPD}

Roflumilast (Daxas ${ }^{\circledR}$, Nycomed, Zurich, Switzerland) has recently been approved in Europe as an add on to bronchodilator treatment for the treatment of severe COPD ( $\mathrm{FEV}_{1} \%$ predicted $<50 \%$ ) associated with chronic bronchitis in adult patients with a history of frequent exacerbations.

So far both short- and long-term romflumilast has been evaluated for effects on lung function, exacerbation rate, and quality of life. The most relevant data supporting the efficacy and safety of roflumilast come from several studies, which also enabled the COPD subset to benefit most from such a therapy to be identified (Table 2).

In an earlier clinical study in which 38 patients with COPD received $500 \mu \mathrm{g}$ roflumilast or placebo once daily for 4 weeks, roflumilast significantly reduced sputum neutrophils and eosinophil counts compared with placebo by $35.5 \%$ (95\% CI 15.6\%-50.7\%; $P=0.002)$ and $50.0 \%(95 \%$ CI $26.8 \%-$ $65.8 \% ; P<0.001$ ), respectively. Roflumilast also significantly reduced the levels of soluble IL-8, neutrophil elastase, eosinophil cationic protein, and alpha(2)-macroglobulin in sputum and the release of TNF- $\alpha$ from blood cells, and also improved lung function (postbronchodilator $\mathrm{FEV}_{1}$ ). ${ }^{37}$

A subsequent phase III, multicenter, double-blind, randomized, placebo-controlled study (The RECORD, M 2-107) was performed in 1411 patients who received either roflumilast $250 \mu \mathrm{g}(\mathrm{n}=576)$, roflumilast $500 \mu \mathrm{g}(\mathrm{n}=555)$, or placebo $(\mathrm{n}=280)$ given orally once daily for 24 weeks. Primary outcomes were represented by postbronchodilator $\mathrm{FEV}_{1}$ and health-related quality of life whereas secondary outcomes included other lung function parameters and COPD exacerbations. Roflumilast significantly improved postbronchodilator $\mathrm{FEV}_{1}$ (by $74 \mathrm{~mL}$ at the lower dose and by $97 \mathrm{~mL}$ at the higher dose compared with placebo; $P<0.0001)$. Roflumilast at the higher dose had the most significant effect on the mean exacerbation rate, the higher dose-group demonstrating the lowest mean number of COPD exacerbations (1.13 excacerbations per patient in placebo group, versus 1.03 in roflumilast 250 $\mu \mathrm{g}$, versus 0.75 in roflumilast $500 \mu \mathrm{g}$ ). This effect was mainly due to the reduction in the number of mild exacerbations $(42 \%$ reduction in number of mild exacerbations with roflumilast $500 \mu \mathrm{g}$ compared with placebo). The most common adverse events were moderate and severe COPD exacerbations and nasopharyngitis. Diarrhea was the most common medicationrelated adverse event followed by nausea and headache. ${ }^{38}$

Table 2 Long-term studies involving roflumilast

\begin{tabular}{|c|c|c|c|c|c|}
\hline Study & Duration & Treatment & $\begin{array}{l}\text { Baseline mean } \\
\text { postbronchodilator } \\
\text { FEV \%pred }\end{array}$ & Sample & Primary endpoint \\
\hline $\begin{array}{l}\text { The RECORD } \\
\text { (M2-107) }\end{array}$ & 24 weeks & $\begin{array}{l}\text { Roflumilast } 250 \mu \mathrm{g} \text {, } \\
\text { roflumilast } 500 \mu \mathrm{g} \text {, } \\
\text { placebo }\end{array}$ & 54 & $N=|4| \mid$ & $\begin{array}{l}\text { Change from baseline in } \\
\text { postbronchodilator FEV } \\
\text { Change from baseline in HRQoL } \\
\text { scores (SGRQ) }\end{array}$ \\
\hline $\begin{array}{l}\text { The OPUS } \\
(M-I I I) \text { and The } \\
\text { RATIO (M-II })\end{array}$ & 52 weeks & $\begin{array}{l}\text { Roflumilast } 500 \mu g \\
\text { once daily or placebo }\end{array}$ & 37 & $\begin{array}{l}\mathrm{N}=2686 \text { (post-hoc } \\
\text { analysis sample) }\end{array}$ & $\begin{array}{l}\text { Change from baseline in } \\
\text { postbronchodilator } F E V_{\text {, }} \text { and } \\
\text { exacerbation rate }\end{array}$ \\
\hline $\begin{array}{l}\text { The EOS } \\
(\mathrm{M} 2-127)\end{array}$ & 24 weeks & $\begin{array}{l}\text { Roflumilast } 500 \mu \mathrm{g}+ \\
\text { salmeterol once daily or } \\
\text { placebo }+ \text { salmeterol }\end{array}$ & $55 \%$ & $N=933$ & $\begin{array}{l}\text { Change from baseline in } \\
\text { prebronchodilator } F E V_{\text {, }}\end{array}$ \\
\hline $\begin{array}{l}\text { The HELIOS } \\
\text { (M 2-I28) }\end{array}$ & 24 weeks & $\begin{array}{l}\text { Roflumilast } 500 \mu \mathrm{g} \text { once } \\
\text { daily + tiotropium or } \\
\text { placebo + tiotropium }\end{array}$ & $55 \%$ & $N=743$ & $\begin{array}{l}\text { Change from baseline in } \\
\text { prebronchodilator FEV, }\end{array}$ \\
\hline $\begin{array}{l}\text { The AURA } \\
(M-124)\end{array}$ & 52 weeks & $\begin{array}{l}\text { Roflumilast } 250 \mu \mathrm{g} \text {, } \\
\text { roflumilast } 500 \mu \mathrm{g} \text {, } \\
\text { placebo }\end{array}$ & $<50 \%$ & $N=1523$ & $\begin{array}{l}\text { Change in prebronchodilator FEV } \\
\text { from baseline } \\
\text { The rate of moderate and severe } \\
\text { exacerbations }\end{array}$ \\
\hline $\begin{array}{l}\text { The HERMES } \\
(M-125)\end{array}$ & 52 weeks & $\begin{array}{l}\text { Roflumilast } 250 \mu \mathrm{g} \text {, } \\
\text { roflumilast } 500 \mu \mathrm{g} \text {, } \\
\text { placebo }\end{array}$ & $<50 \%$ & $N=1568$ & $\begin{array}{l}\text { Change in prebronchodilator FEV } \\
\text { from baseline } \\
\text { The rate of moderate and severe } \\
\text { exacerbations }\end{array}$ \\
\hline
\end{tabular}

Abbreviations: HRQoL, health-related quality of life; SGRQ, St. George's Respiratory Questionnaire. 


\section{OPUS and RATIO studies}

The OPUS (M2-111) and the RATIO (M2-112) were replicated, randomized, double-blind, placebo-controlled studies evaluating the effects of oral roflumilast $500 \mu \mathrm{g}$ versus placebo once daily for 52 weeks in COPD patients with moderate to severe disease.

The RATIO study enrolled a total of 1513 patients with a mean postbronchodilator $\mathrm{FEV}_{1}$ of $41 \%$. The primary efficacy endopoints were postbronchodilator $\mathrm{FEV}_{1}$ and exacerbation rate, whereas health-related quality of life was the secondary endpoint. ${ }^{39,40}$ Roflumilast significantly increased $\mathrm{FEV}_{1}(39 \mathrm{~mL}, P=0.001)$ but had no significant therapeutic effect on the other 2 endpoints; in the subset of the patients with GOLD IV stage of the disease, roflumilast improved lung function and significantly reduced mean exacerbation rate (1.01 versus 1.59 exacerbations per patient per year, $P=0.024) .{ }^{40}$ Adverse events related to roflumilast treatment were diarrhea, nausea, and headache, which resolved without intervention as the treatment continued.

In a post-hoc pooled analysis including a total of 2686 patients in both the OPUS and the RATIO studies having a mean postbronchodilator $\mathrm{FEV}_{1}$ of $37 \%$, "roflumilast responders" had a clinical phenotype of chronic bronchitis, were frequent exacerbators, and had a postbronchodilator $\mathrm{FEV}_{1}<50 \%$. In this subset of patients roflumilast reduced the exacerbation rate by about $26 \%(P=0.001)$ compared with placebo, whereas in the subset with emphysema its effect was comparable to that of placebo. A significant therapeutic benefit was also seen in patients also receiving concomitant inhaled corticosteroids in whom roflumilast was found to reduce the exacerbation rate by $18.8 \%$ $(P=0.014) .39,41,42$

\section{EOS and HELIOS studies}

The EOS and HELIOS studies compared the efficacy and safety of roflumilast versus placebo in patients with COPD receiving long-acting bronchodilators such as salmeterol (EOS, M2-127) or tiotropium (HELIOS, M2-128). General inclusion criteria were represented by patients with stable COPD, current or ex-smokers, with a smoking history of at least 10 pack-years, and postbronchodilator $\mathrm{FEV}_{1} \%$ predicted $40 \%$ to $70 \%$. Specific inclusion criteria were presence of respiratory symptoms of chronic bronchitis, chronic cough, and sputum production and by the frequent use of $\beta 2$ agonists while on tiotropium therapy of at least 3 months' duration. ${ }^{43}$

After an initial 4-week run in period during which patients were given a placebo tablet once daily, patients with no moderate to severe COPD exacerbations during this period were randomized to either roflumilast $500 \mu \mathrm{g}$ once daily in the morning or placebo for 24 weeks. ${ }^{43}$

The primary endpoint in both studies was change in prebronchodilator $\mathrm{FEV}_{1}$, and the secondary endpoints included postbronchodilator $\mathrm{FEV}_{1}, \mathrm{FVC}$, and Transition Dyspnea Index score, the Shortness of Breath Questionnaire, exacerbation rate, and the use of rescue medications. Safety endpoints were also included.

The EOS study enrolled 933 patients, 466 in the treatment and 467 in the placebo arms, respectively, whereas the HELIOS study enrolled 743 patients, 371 in the treatment arm and 372 in the placebo arm. The populations in both studies were uniform in terms of age, male predominance, the higher prevalence of ex-smokers, and adherence rate. All patients in the HELIOS study presented with chronic cough and sputum. The 2 populations differed in terms of use of rescue medication, which was higher at baseline in the HELIOS study. ${ }^{43}$

In both trials probability of study discontinuation was higher in patients receiving roflumilast and significantly higher in patients receiving salmeterol. Roflumilast improved lung function overall by increasing prebronchodilator and postbronchodilator $\mathrm{FEV}_{1}$, and prebronchodilator and postbronchodilator $\mathrm{FVC}$, and $\mathrm{FEV}_{1}$ improvements were shown in all disease severity subsets, irrespective of the smoking status.

In the EOS study, roflumilast significantly prolonged the median time to first moderate or severe exacerbation and significantly reduced the proportion of patients experiencing an exacerbation throughout the study period in general, and the proportion of patients with moderate or severe exacerbation in particular.

In the HELIOS study roflumilast significantly reduced the overall proportion of patients with an exacerbation and significantly prolonged median time to first exacerbation; it also reduced dyspnea severity, and improved health-related quality of life and significantly reduced the use of rescue medication. ${ }^{43}$

\section{AURA and HERMES studies}

The AURA (M-124) and the HERMES (M-125) studies were placebo-controlled, double-blind, multicenter studies in patients with severe and very severe COPD (postbronchodilator $\mathrm{FEV}_{1}<50 \%$ ), cough, and sputum production and at least 1 exacerbation requiring systemic corticosteroids in the previous year. After a 4-week run in period, during which patients were given a placebo tablet once a day, their use of 
short-acting bronchodilators, and cough and sputum production were recorded, they were randomized to receive either roflumilast $500 \mu \mathrm{g}$ or placebo once daily for the next 52 weeks, and were allowed to take short- and long-acting $\beta 2$ agonists but not long-acting anticholinergics or inhaled corticosteroids. The primary endpoints were the change in prebronchodilator $\mathrm{FEV}_{1}$ from baseline and the rate of moderate and severe exacerbations. The secondary endpoints included postbronchodilator $\mathrm{FEV}_{1}$ change from baseline, time to mortality, systemic inflammation (assessed with C-reactive protein), health utility scores, dyspnea change over study period, and safety. ${ }^{44-46}$

The AURA study included 1523 patients, 765 in the roflumilast arm and 758 in the placebo arm, whereas the HERMES study included 1568 patients, 772 in the roflumilast arm and 796 in the placebo arm. In both studies a total of 1537 patients received roflumilast and 1554 received placebo (pooled analysis). Roflumilast improved the primary endpoints in each study. A pooled analysis of both studies showed: prebronchodilator $\mathrm{FEV}_{1} 39 \mathrm{~mL}(P=0.0003)$ in AURA study, $58 \mathrm{~mL}(P<0.0001)$ in HERMES study, and $48 \mathrm{~mL}(P<0.0001)$ in both studies; moderate or severe exacerbation mean rate 1.08 versus 1.27 exacerbations per patient per year $(P=0.0278)$ in the AURA study, 1.21 versus 1.49 exacerbations per patient per year $(P=0.0035)$ in the HERMES study and 1.14 versus 1.37 exacerbations per patient per year $(P=0.0003)$ in both studies. ${ }^{44}$ The effect on exacerbations was manifested mainly in moderate exacerbations, as the therapeutic effect on severe exacerbations was comparable with that in placebo. Roflumilast also significantly improved postbronchodilator $\mathrm{FEV}_{1}$ and reduced dyspnea severity but had no effect on systemic inflammation, time to mortality, and health utility scores. ${ }^{44}$

In the pooled analysis adverse events were reported in $1040(67 \%)$ of patients receiving roflumilast and $963(62 \%)$ patients receiving placebo; the most frequent adverse events leading to roflumilast discontinuation were nausea, diarrhea and headache. ${ }^{44}$

\section{PDE4 inhibitors use in COPD: limitations and side effects}

The initial gastrointestinal side-effects such as nausea or diarrhea reported with the nonselective PDE inhibitor theophylline drew the attention to the potential physiological involvement of these enzymes in prevention of such effects.

Because PDE4s selective inhibition was found to be associated with similar effects, further research was done to identify the pathogenic role of the inhibition of these enzymes in emetogenesis. It was discovered that the emesis mechanism is neuronal and related to the increase of cAMP by theophylline or by selective PDE4 inhibitors in area postrema. $^{47}$

Among the 4 PDE4 isoforms identified to date, A, B, C, and D, PDE4D inhibition was identified as having the highest emetogenic potential, as PDE4D gene deletion was associated with a significant reduction in the emesis. ${ }^{48-50}$

In clinical studies evaluating roflumilast, the incidence of adverse events was about $16 \%$ with roflumilast compared with $5 \%$ with placebo. The most commonly reported adverse events were: diarrhea (5.9\%), weight loss (3.4\%), nausea (2.9\%), abdominal pain $(1.9 \%)$, and headache $(1.7 \%){ }^{26}$ These adverse reactions occurred mainly during the first weeks of therapy and disappeared subsequently with treatment continuation. Roflumilast therapy was associated with an increased risk of psychiatric disorders such as insomnia, anxiety, nervousness, and depression. ${ }^{26}$ Suicidal ideation and behavior were also rarely detected in clinical trials, and based on these findings roflumilast is not recommended in patients with a history of depression associated with suicidal ideation or behavior. ${ }^{26}$

Other concerns related to PDE4 inhibition were, fortunately, raised based only on results of preclinical experiments: there have been reports of mesenteric vasculitis, heart failure, or arrhythmia. ${ }^{9,51}$

Another important issue is the proinflammatory effects of roflumilast detected at very high doses $(100 \mathrm{mg} / \mathrm{kg})$, again in preclinical studies. It has been suggested that PDE4 inhibitors may have proinflammatory properties. ${ }^{52}$ However at the currently approved roflumilast dosage, the occurrence of such effects is almost impossible.

\section{PDE4 inhibitors: perspective issues}

Based on the existing large body of clinical data, the efficacy of roflumilast is well established and the place of this type of compound in COPD therapy is quite well delineated. However some other issues remain to be clarified, including the safety profile and the systemic anti-inflammatory effects of roflumilast in COPD.

The major safety issue is the emetogenic potential of roflumilast, given its inhibitory effects on the PDE4D isoform. However this effect, even at the therapeutic dose currently approved, has rarely been reported, and further research is needed in order to clarify the risk factors for this event. 
COPD is currently recognized as a disease of the airways in which local inflammation may be accompanied by systemic inflammation. Given that roflumilast is an oral PDE4 inhibitor and exerts systemic effects, it can presumably also reduce systemic inflammation. Such effects have not yet been documented and their demonstration would provide additional data in support of the use of roflumilast in COPD.

Other PDE4 inhibitors are currently under development in an attempt to overcome side-effects such as nausea and vomiting reported with the PDE4 inhibitors. Among the 4 PDE4 isoforms, PDE4B exerted the most potent proinflammatory effects: in mice lipopolysaccharide challenge was associated with an increase in PDE4B expression and activity and with an increase in TNF- $\alpha$ in the peripheral leucocytes and peritoneal macrophages, responses that were absent or blunted in PDE4B-deficient mice. ${ }^{53,54}$ Furthermore in mice asthma, PDE4B was demonstrated to play a crucial role in the development of allergen-induced Th2-driven airway inflammation. ${ }^{55}$

Such results have supported the development of selective PDE4B inhibitors, and recently 4-(substituted amino)-1alkyl-pyrazolo[3,4-b]pyridine-5-carboxamides were reported recently to be potent and selective PDE4B inhibitors which inhibited lipopolysaccharide-induced TNF- $\alpha$ production from isolated human peripheral blood mononuclear cells. ${ }^{56}$

Other PDE4 inhibitors are currently in development either as oral or as inhalation formulations. Roflumilast has been evaluated as an inhaled formulation in a rat model of OVA-induced asthma and its anti-inflammatory and bronchodilator effects have been demonstrated ${ }^{57}$ However to date inhaled roflumilast has been assessed in the COP setting. Another inhaled PDE4 inhibitor, 1-[[5-(1(S)-aminoethly)-2[8-methoxy-2-(triflurormethyl)-5-quinolinyl]-4-oxazolyl] carbonyl]-4(R)-[(cyclopropylcarbonyl)amino]-L-proline, ethyl ester xinafoate salt, was also recently found in preclinical studies to inhibit the human PDE4 and to exert antiinflammatory and bronchodilator effects which were synergistic with corticosteroids or $\beta 2$ agonists. ${ }^{58}$

\section{Conclusion}

Roflumilast is the first selective PDE4 inhibitor approved in Europe as an add-on anti-inflammatory therapy in patients with symptomatic severe COPD with frequent exacerbations. This indication is supported mainly by the substantial clinical data demonstrating its ability to reduce exacerbation rate and to improve lung function in this disease subset.
However two main issues are still pending: long-term safety and systemic anti-inflammatory effects. If the safety profile associated with long-term use proves to be similar to that shown in the clinical studies performed during its clinical development, the "clinical position" of roflumilast as a safe and effective medication for COPD therapy would be strengthened. Furthermore such data would help to detect potential risk factors for emetogenesis, which is the main side effect associated with roflumilast use.

Documentation of the systemic anti-inflammatory effects would further support the efficacy of roflumilast for COPD.

To conclude, roflumilast is the newest anti-inflammatory therapy which can be used in COPD and can significantly affect disease progression.

\section{Disclosure}

The author declares no conflicts of interest.

\section{References}

1. The GOLD Workshop Report (Updated 2008): Global strategy for the diagnosis, management and prevention of chronic obstructive pulmonary disease. www.goldcopd.com.

2. Burge PS, Calverley PM, Jones PW, Spencer S, Anderson JA, Maslen TK. Randomised, double blind, placebo controlled study of fluticasone propionate in patients with moderate to severe chronic obstructive pulmonary disease: the ISOLDE trial. BMJ. 2003;20(7245): 1297-1303.

3. Calverley PM, Boonsawat W, Cseke Z, Zhong N, Peterson S, Olsson H. Maintenance therapy with budesonide and formoterol in chronic obstructive pulmonary disease. Eur Respir J. 2003;22(6):912-919.

4. Macnee W. Pathogenesis of chronic obstructive pulmonary disease. Proc Am Thorac Soc. 2005;2(4):258-266; discussion 290-251.

5. Cosio MG, Majo J, Cosio MG. Inflammation of the airways and lung parenchyma in COPD: role of T cells. Chest. 2002;121(5 Suppl): $160 \mathrm{~S}-165 \mathrm{~S}$

6. Majo J, Ghezzo H, Cosio MG. Lymphocyte population and apoptosis in the lungs of smokers and their relation to emphysema. Eur Respir J. 2001;17(5):946-953.

7. Russell RE, Thorley A, Culpitt SV, et al. Alveolar macrophagemediated elastolysis: roles of matrix metalloproteinases, cysteine, and serine proteases. Am J Physiol Lung Cell Mol Physiol. 2002;283(4): L867-L873.

8. Stockley RA. Neutrophils and the pathogenesis of COPD. Chest. 2002;121(5 Suppl):151S-155S.

9. Boswell-Smith V, Spina D. PDE4 inhibitors as potential therapeutic agents in the treatment of COPD-focus on roflumilast. Int J Chron Obstruct Pulmon Dis. 2007;2(2):121-129.

10. Torphy TJ. Phosphodiesterase isozymes: molecular targets for novel antiasthma agents. Am J Respir Crit Care Med. 1998;157(2):351-370.

11. Banner KH, Page CP. Theophylline and selective phosphodiesterase inhibitors as anti-inflammatory drugs in the treatment of bronchial asthma. Eur Respir J. 1995;8(6):996-1000.

12. Barnes PJ. Theophylline in chronic obstructive pulmonary disease: new horizons. Proc Am Thorac Soc. 2005;2(4):334-339; discussion 340-331.

13. Barnes PJ. Theophylline: new perspectives for an old drug. Am J Respir Crit Care Med. 2003;167(6):813-818.

14. Rabe KF, Magnussen H, Dent G. Theophylline and selective PDE inhibitors as bronchodilators and smooth muscle relaxants. Eur Respir J. 1995;8(4):637-642. 
15. Rabe KF, Tenor H, Dent G, Schudt C, Liebig S, Magnussen H. Phosphodiesterase isozymes modulating inherent tone in human airways: identification and characterization. Am J Physiol. 1993; 264(5 Pt 1):L458-L464.

16. McKay SE, Howie CA, Thomson AH, Whiting B, Addis GJ. Value of theophylline treatment in patients handicapped by chronic obstructive lung disease. Thorax. 1993;48(3):227-232.

17. Murciano D, Auclair MH, Pariente R, Aubier M. A randomized, controlled trial of theophylline in patients with severe chronic obstructive pulmonary disease. $N$ Engl J Med. 1989;320(23):1521-1525.

18. Culpitt SV, De Matos C, Russell RE, Donnelly LE, Rogers DF, Barnes PJ. Effect of theophylline on induced sputum inflammatory indices and neutrophil chemotaxis in chronic obstructive pulmonary disease. Am J Respir Crit Care Med. 2002;165(10):1371-1376.

19. Kobayashi M, Nasuhara Y, Betsuyaku T, et al. Effect of low-dose theophylline on airway inflammation in COPD. Respirology. 2004;9(2): 249-254.

20. Jaffar ZH, Sullivan P, Page C, Costello J. Low-dose theophylline modulates T-lymphocyte activation in allergen-challenged asthmatics. Eur Respir J. 1996;9(3):456-462.

21. Djukanovic R, Finnerty JP, Lee C, Wilson S, Madden J, Holgate ST. The effects of theophylline on mucosal inflammation in asthmatic airways: biopsy results. Eur Respir J. 1995;8(5):831-833.

22. Finnerty JP, Lee C, Wilson S, Madden J, Djukanovic R, Holgate ST. Effects of theophylline on inflammatory cells and cytokines in asthmatic subjects: a placebo-controlled parallel group study. Eur Respir J. 1996; 9(8):1672-1677.

23. Iiboshi H, Ashitani JI, Katoh S, et al. Long-term treatment with theophylline reduces neutrophils, interleukin- 8 and tumor necrosis factoralpha in the sputum of patients with chronic obstructive pulmonary disease. Pulm Pharmacol Ther. 2005.

24. Cortijo J, Bou J, Beleta J, et al. Investigation into the role of phosphodiesterase IV in bronchorelaxation, including studies with human bronchus. Br J Pharmacol. 1993;108(2):562-568.

25. Hatzelmann A, Schudt C. Anti-inflammatory and immunomodulatory potential of the novel PDE4 inhibitor roflumilast in vitro. J Pharmacol Exp Ther. 2001;297(1):267-279.

26. European Medicines Agency. Daxas: EPAR - Product Information (2010).

27. Wollin L, Bundschuh DS, Wohlsen A, Marx D, Beume R. Inhibition of airway hyperresponsiveness and pulmonary inflammation by roflumilast and other PDE4 inhibitors. Pulm Pharmacol Ther. 2006; 19(5):343-352.

28. Wollin L, Marx D, Wohlsen A, Beume R. Roflumilast inhibition of pulmonary leukotriene production and bronchoconstriction in ovalbumin-sensitized and -challenged Guinea pigs. J Asthma. $2005 ; 42(10): 873-878$.

29. Kumar RK, Herbert C, Thomas PS, et al. Inhibition of inflammation and remodeling by roflumilast and dexamethasone in murine chronic asthma. J Pharmacol Exp Ther. 2003;307(1):349-355.

30. Sabatini F, Petecchia L, Boero S, et al. A phosphodiesterase 4 inhibitor, roflumilast N-oxide, inhibits human lung fibroblast functions in vitro. Pulm Pharmacol Ther. 23(4):283-291.

31. Fitzgerald M, Spicer D, Mcaulay AE, Wollin L, Beume R. Roflumilast but not methylprednisolone inhibited cigarette smoke-induced pulmonary inflammation in guinea pigs. Eur Respir J Suppl. 2006;(663s), $2010 ; \mathrm{P} 3850$.

32. Hardaker E, Freeman MS, Dale N, Raza F, Mok J, Banner KH, et al. Characterisation of a model that mimicks aspects of the hyperinflammatory response observed during an acute exacerbation of COPD. Am J Respir Crit Care Med. 2009;(179):A5351.

33. Hatzelmann A, Morcillo EJ, Lungarella G, et al. The preclinical pharmacology of roflumilast - a selective, oral phosphodiesterase 4 inhibitor in development for chronic obstructive pulmonary disease. Pulm Pharmacol Ther. 23(4):235-256.
34. Martorana PA, Beume R, Lucattelli M, Wollin L, Lungarella G. Roflumilast fully prevents emphysema in mice chronically exposed to cigarette smoke. Am J Respir Crit Care Med. 2005;172(7): 848-853.

35. Martorana PA, Lunghi B, Lucattelli M, De Cunto G, Beume R, Lungarella G. Effect of roflumilast on inflammatory cells in the lungs of cigarette smoke-exposed mice. BMC Pulm Med. 2008;8:17.

36. Mata M, Sarria B, Buenestado A, Cortijo J, Cerda M, Morcillo EJ. Phosphodiesterase 4 inhibition decreases MUC5AC expression induced by epidermal growth factor in human airway epithelial cells. Thorax. 2005;60(2):144-152.

37. Grootendorst DC, Gauw SA, Verhoosel RM, et al. Reduction in sputum neutrophil and eosinophil numbers by the PDE4 inhibitor roflumilast in patients with COPD. Thorax. 2007;62(12):1081-1087.

38. Rabe KF, Bateman ED, O'Donnell D, Witte S, Bredenbroker D, Bethke TD. Roflumilast - an oral anti-inflammatory treatment for chronic obstructive pulmonary disease: a randomised controlled trial. Lancet. 2005;366(9485):563-571.

39. Effect of Roflumilast on Exacerbation Rate in Patients With Chronic Obstructive Pulmonary Disease. Ratio-Study. (BY217/M2-112).

40. Calverley PM, Sanchez-Toril F, McIvor A, Teichmann P, Bredenbroeker D, Fabbri LM. Effect of 1-year treatment with roflumilast in severe chronic obstructive pulmonary disease. Am J Respir Crit Care Med. 2007;176(2):154-161.

41. Martinez F, Calverley PMA, Goehring UM, Rennard SI. Defining patient populations in COPD: experience with roflumilast. 2010.

42. OPUS Study: Effect of Roflumilast on Exacerbation Rate in Patients With Chronic Obstructive Pulmonary Disease (BY217/M2-111).

43. Fabbri LM, Calverley PM, Izquierdo-Alonso JL, et al. Roflumilast in moderate-to-severe chronic obstructive pulmonary disease treated with longacting bronchodilators: two randomised clinical trials. Lancet. 2009;374(9691):695-703

44. Calverley PM, Rabe KF, Goehring UM, Kristiansen S, Fabbri LM, Martinez FJ. Roflumilast in symptomatic chronic obstructive pulmonary disease: two randomised clinical trials. Lancet. 2009;374(9691): 685-694.

45. Effect of Roflumilast on Exacerbation Rate in Patients With Chronic Obstructive Pulmonary Disease (COPD): The AURA Study (BY217/ M2-124).

46. Effect of Roflumilast on Exacerbation Rate in Patients With Chronic Obstructive Pulmonary Disease (COPD): The HERMES Study (BY217/ M2-125).

47. Carpenter DO, Briggs DB, Knox AP, Strominger N. Excitation of area postrema neurons by transmitters, peptides, and cyclic nucleotides. J Neurophysiol. 1988;59(2):358-369.

48. Houslay MD, Adams DR. PDE4 cAMP phosphodiesterases: modular enzymes that orchestrate signalling cross-talk, desensitization and compartmentalization. Biochem J. 2003;370(Pt 1):1-18.

49. Lamontagne S, Meadows E, Luk P, et al. Localization of phosphodiesterase- 4 isoforms in the medulla and nodose ganglion of the squirrel monkey. Brain Res. 2001;920(1-2):84-96.

50. Robichaud A, Stamatiou PB, Jin SL, et al. Deletion of phosphodiesterase $4 \mathrm{D}$ in mice shortens alpha(2)-adrenoceptor-mediated anesthesia, a behavioral correlate of emesis. J Clin Invest. 2002;110(7):1045-1052.

51. Lehnart SE, Wehrens Xh, Reiken S, et al. Phosphodiesterase 4D deficiency in the ryanodine-receptor complex promotes heart failure and arrhythmias. Cell. 2005;123(1):25-35.

52. McCluskie K, Klein U, Linnevers C, et al. Phosphodiesterase type 4 inhibitors cause proinflammatory effects in vivo. J Pharmacol Exp Ther. 2006;319(1):468-476.

53. Jin SL, Conti M. Induction of the cyclic nucleotide phosphodiesterase PDE4B is essential for LPS-activated TNF-alpha responses. Proc Natl Acad Sci U S A. 2002;99(11):7628-7633.

54. Jin SL, Lan L, Zoudilova M, Conti M. Specific role of phosphodiesterase 4B in lipopolysaccharide-induced signaling in mouse macrophages. J Immunol. 2005;175(3):1523-1531. 
55. Jin SL, Goya S, Nakae S, et al. Phosphodiesterase 4B is essential for $\mathrm{T}(\mathrm{H}) 2$-cell function and development of airway hyperresponsiveness in allergic asthma. J Allergy Clin Immunol. 126(6):1252-1259 e1212.

56. Hamblin JN, Angell TD, Ballantine SP, et al. Pyrazolopyridines as a novel structural class of potent and selective PDE4 inhibitors. Bioorg Med Chem Lett. 2008;18(14):4237-4241.
57. Chapman RW, House A, Jones H, et al. Effect of inhaled roflumilast on the prevention and resolution of allergen-induced late phase airflow obstruction in Brown Norway rats. Eur J Pharmacol. 2007;571(2-3): 215-221.

58. Chapman RW, House A, Richard J, et al. Pharmacology of a potent and selective inhibitor of PDE4 for inhaled administration. Eur J Pharmacol. 643(2-3):274-281.

International Journal of COPD

\section{Publish your work in this journal}

The International Journal of COPD is an international, peer-reviewed journal of therapeutics and pharmacology focusing on concise rapid reporting of clinical studies and reviews in COPD. Special focus is given to the pathophysiological processes underlying the disease, intervention programs, patient focused education, and self management
Dovepress

protocols. This journal is indexed on PubMed Central, MedLine and CAS. The manuscript management system is completely online and includes a very quick and fair peer-review system, which is all easy to use. Visit http://www.dovepress.com/testimonials.php to read real quotes from published authors.

Submit your manuscript here: http://www.dovepress.com/international-journal-of-copd-journa 